\title{
Biphasic Electrical Currents Stimulation Promotes both Proliferation and Differentiation of Fetal Neural Stem Cells
}

\author{
Keun-A Chang ${ }^{19}$, Jin Won Kim ${ }^{39}$, Jeong a Kim ${ }^{19}$, Sungeun Lee ${ }^{3}$, Saeromi Kim ${ }^{1}$, Won Hyuk Suh4, Hye-Sun \\ $\mathrm{Kim}^{1,2}$, Sunghoon Kwon ${ }^{3}$, Sung June $\mathrm{Kim}^{3 *}$, Yoo-Hun Suh ${ }^{1 *}$
}

1 Department of Pharmacology, College of Medicine, Neuroscience Research Institute, MRC, Seoul National University, Seoul, South Korea, 2 Department of Pharmacology, Bundang Hospital, College of Medicine, Seoul National University, Bundang-Gu, Sungnam, Kyungki, South Korea, $\mathbf{3}$ School of Electrical Engineering and Computer Science, Seoul National University, Seoul, Republic of Korea, 4 Department of Bioengineering, University of California, Berkeley, California, United States of America

\begin{abstract}
The use of non-chemical methods to differentiate stem cells has attracted researchers from multiple disciplines, including the engineering and the biomedical fields. No doubt, growth factor based methods are still the most dominant of achieving some level of proliferation and differentiation control - however, chemical based methods are still limited by the quality, source, and amount of the utilized reagents. Well-defined non-chemical methods to differentiate stem cells allow stem cell scientists to control stem cell biology by precisely administering the pre-defined parameters, whether they are structural cues, substrate stiffness, or in the form of current flow. We have developed a culture system that allows normal stem cell growth and the option of applying continuous and defined levels of electric current to alter the cell biology of growing cells. This biphasic current stimulator chip employing ITO electrodes generates both positive and negative currents in the same culture chamber without affecting surface chemistry. We found that biphasic electrical currents (BECs) significantly increased the proliferation of fetal neural stem cells (NSCs). Furthermore, BECs also promoted the differentiation of fetal NSCs into neuronal cells, as assessed using immunocytochemistry. Our results clearly show that BECs promote both the proliferation and neuronal differentiation of fetal NSCs. It may apply to the development of strategies that employ NSCs in the treatment of various neurodegenerative diseases, such as Alzheimer's and Parkinson's diseases.
\end{abstract}

Citation: Chang K-A, Kim JW, Kim Ja, Lee S, Kim S, et al. (2011) Biphasic Electrical Currents Stimulation Promotes both Proliferation and Differentiation of Fetal Neural Stem Cells. PLoS ONE 6(4): e18738. doi:10.1371/journal.pone.0018738

Editor: Dimas Tadeu Covas, University of Sao Paulo - USP, Brazil

Received October 18, 2010; Accepted March 15, 2011; Published April 13, 2011

Copyright: 2011 Chang et al. This is an open-access article distributed under the terms of the Creative Commons Attribution License, which permits unrestricted use, distribution, and reproduction in any medium, provided the original author and source are credited.

Funding: This work was financially supported by Bundang Hospital Research fund (03 - 2007 - 008), in part by WCU program (R33-10167) of the Ministry of Education, and in part by the Conversing Research Center Program (2009-0082268) through the National Research Foundation of Korea (NRF) funded by the Ministry of Education, Science and Technology, the Republic of Korea. Also, this work was supported by the Technology Innovation Program (10033657) funded by the Ministry of Knowledge Economy (MKE) of Korea and the Interdisciplinary Research Initiatives Program by College of Engineering (or College of Natural Sciences) and College of Medicine, Seoul National University (2007). The funders had no role in study design, data collection and analysis, decision to publish, or preparation of the manuscript.

Competing Interests: The authors have declared that no competing interests exist.

*E-mail: yhsuh@snu.ac.kr (YH-S); kimsj@snu.ac.kr (S-JK)

9 These authors contributed equally to this work.

\section{Introduction}

Neural stem cells (NSCs) are self-renewing cells that maintain the capability to differentiate into the major cell types of the brain. Several groups have consistently demonstrated that NSGs in the developing and adult brain generate mature cells of all neural lineages, including astrocytes, oligodendrocytes, and neurons ([1], [2], [3]). Embryonic central nervous tissue derived NSCs can spontaneously (after factor removal) differentiated into astrocytes, oligodendrocytes, and neurons in an approximate ratio of 25:5:1, respectively. ([2], [4]).

NSCs are being considered for important therapeutic strategies for the treatment of various neurodegenerative diseases including Alzheimer's and Parkinson's diseases. NSCs taken from human fetuses have shown a remarkable ability to replace endogenous, degenerating dopamine neurons and to ameliorate disease symptoms [4]. It has already been shown that hippocampus- derived NSGs can differentiate into excitatory and inhibitory neurons expressing the appropriate neurotransmitters [5] and/or form functional synapses with co-cultured neurons or within the mouse brain [6].

For clinical therapy using NSCs, it is essential to secure a large number of differentiated NSCs. The transplantation of differentiated NSCs would enhance engraftment efficiency and clinical efficiency [7]. Although much work has been done to elucidate the regulatory mechanisms that control the proliferation and differentiation of endogenous NSGs, this topic requires further investigation. The manipulation of central nervous system (CNS) stem cells in vitro could be useful for understanding of the mechanisms that control the proliferation and fate choice of NSCs. Fetal and adult stem cells can adopt neuronal and glial fates in vitro ([8], [9], [10], [11]) in response to signals that control the early steps in fate choice [10]. Previous studies have shown the regulatory effects of growth factors on the differentiation of CNS 
precursor cells into different types of neurons ([5], [12], [13], [14], [15]). In addition, multiple stages of neurogenesis, including progenitor proliferation, neural differentiation, and neural maturation, have been shown to be regulated by neural activity ([16], [17]).

In this study, we engineered a biphasic electrical current stimulator chip (Figure 1) that modulates electrical fields on living cells to investigate the effects of electric fields on fetal NSC proliferation and differentiation processes. Freshly isolated NSGs were cultured in a custom-made electrostimulation culture system (Figure 2), which involved the generation of both positive and negative currents inside the six individual culture chambers without detrimental effects and heterogeneity. It is known that the physiological function of in vitro cultured cells could be dramatically altered in response to physical stimuli including electromagnetic field, mechanical force and heat treatment [7]. Charge-balanced BEC is coupled with changes in an electromagnetic field. It can also avoid cell damage by charge accumulation and decrease of stimulation efficiency by charged protein accumulation. The BEG culture system surface was designed to incorporate a conductive and optically transparent layer of indium tin oxide (ITO) that facilitated both optical observation and direct electrical stimulation in liquid phase at $37{ }^{\circ} \mathrm{C}$ and $5 \% \mathrm{CO}_{2}$. The custom designed biphasic electrical current stimulator chip (Figure 1) allowed easy access to control the duration and amplitude of electric currents being applied to the NSCs. We hypothesized that NSC proliferation and differentiation will be affected differently by how the electrical currents are modulated.

\section{Results}

Biphasic electrical current stimulator chip and In Vitro culture system

The waveforms of the fabricated BEC stimulator chip were tested. Measured amplitudes and durations showed good linear characteristic against set levels. Although the waveforms of positive and negative phases are not completely symmetric, the DC potential by charge accumulation was not observed. We believe that, during the culture period, the accumulated charges will have discharged by electrical short circuit thus not significantly affecting cell proliferation. In general, continuous BEC stimulation without short circuit generates a constant DC potential by charges accumulated at the parasitic capacitance of the electrodeelectrolyte interface. Power consumption of a BEG stimulator chip was ideal enough to maintain a stable BEC stimulation for 7 days of culturing inside the incubator.

The In vitro BEG culture system (Figure 2), composed of Indium Tin Oxide (ITO) glasses, Teflon jigs, printed circuit boards (PCBs) and elastomer O-rings, did not induce conspicuous cell death. The elatomer O-rings completely blocked the leakage of culture media, and $\mathrm{PCBs}$ that can influence cell death were isolated from NSGs and culture media. ITO covered glass was transparent enough to observe the morphology and growth of cells under stimulation during the culture period. In addition, the impedance values of ITO glasses were so uniform that BEC from a stimulator chip was distributed equally to all six-culture chambers.
(A)

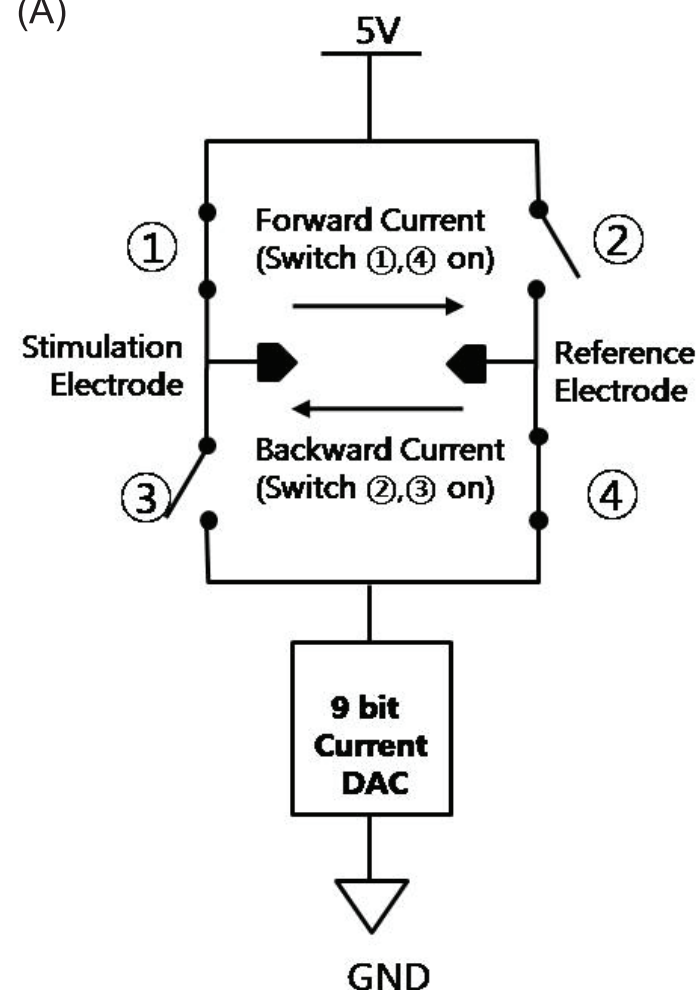

(B)

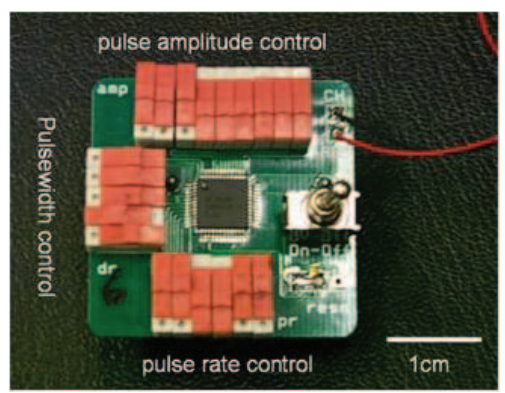

(C)

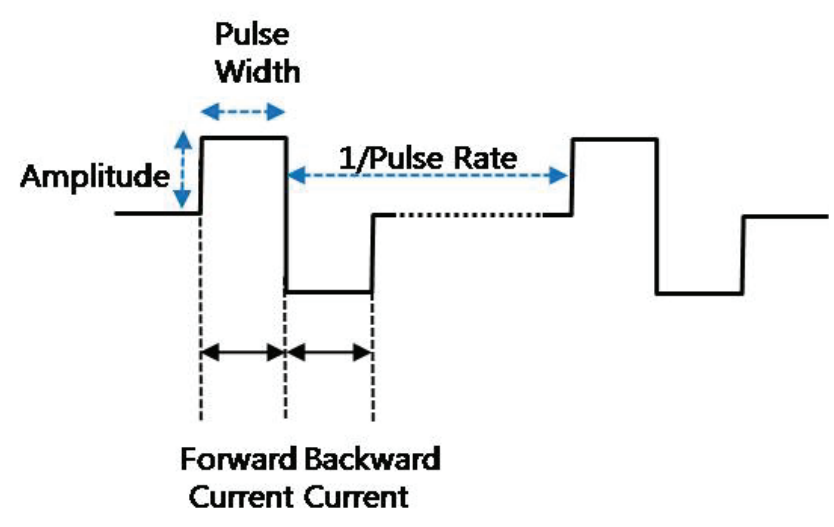

Figure 1. Biphasic electrical current stimulator. (A) A circuit diagram: Biphasic current is generated by the complementary switching between (1), (4) and (2), (3) switches. (B) A top view including the on/off switches for amplitude, duration, and pulse rate setting. (C) Current pulses. doi:10.1371/journal.pone.0018738.g001 
(A)

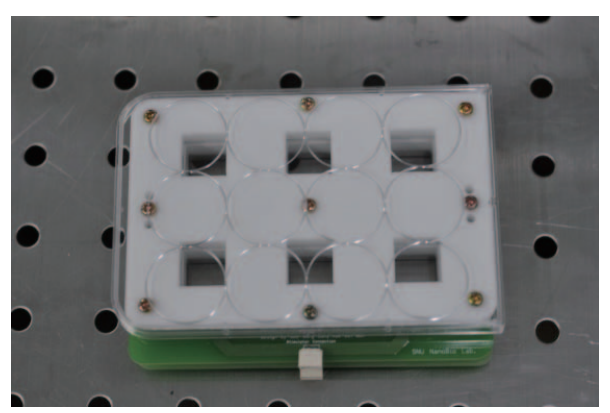

(C)

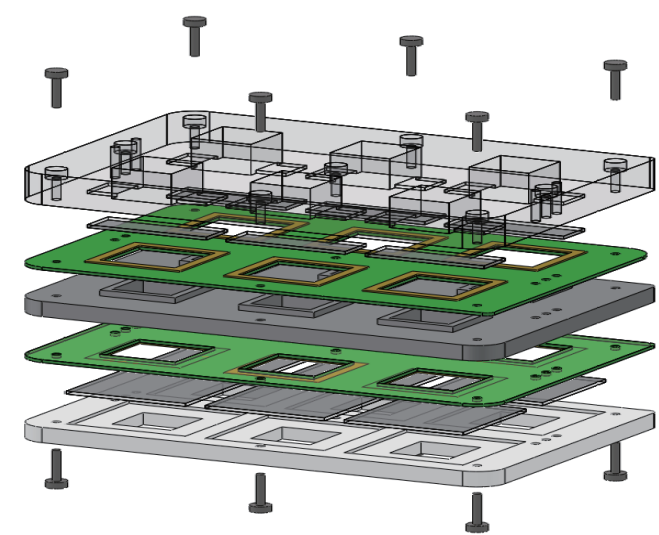

(B)

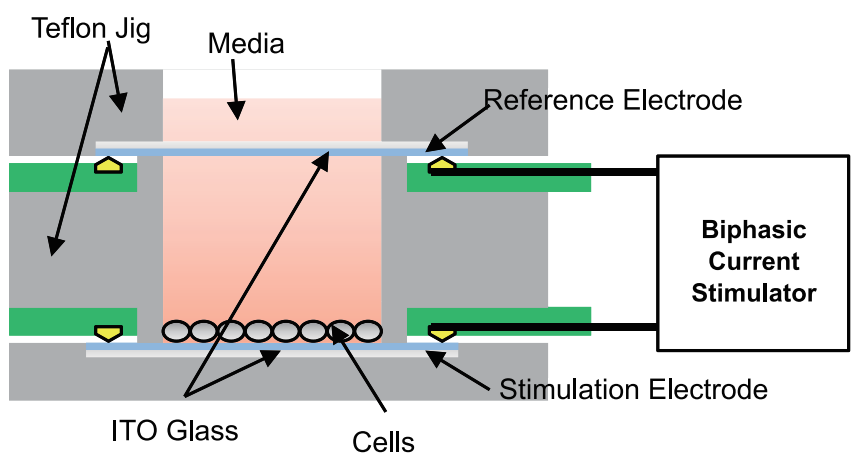

(C)

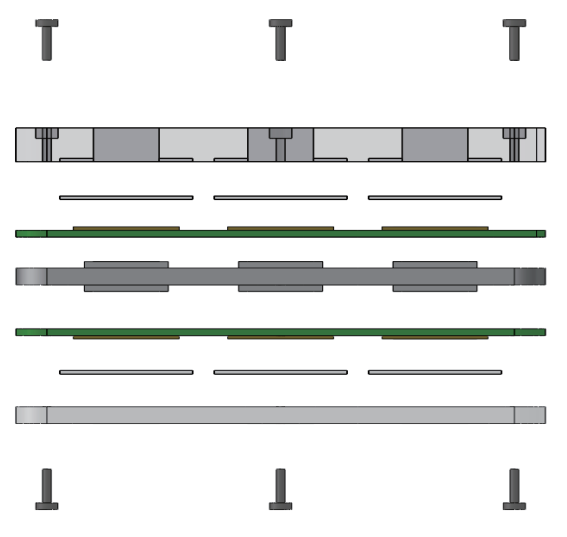

Figure 2. The schematic diagrams of the Teflon culture dish. The Teflon ${ }^{\circledR}$ culture dish and the ITO-deposited glass plates for culturing the neural stem cells are connected to a biphasic current stimulator. Each well is connected in a shunt electrical configuration, forming a 6-well culture system. (A) Photo of the culture chamber. (B) Schematic diagram of cross section of the culture chamber. (C) $3 D$ view of the setup. (D) Side view of the setup.

doi:10.1371/journal.pone.0018738.g002

\section{Electrical stimulation by BEC increases the proliferation of fetal NSCs}

In this study, we investigated the effects of electrical stimulation by BEC on the proliferation of NSCs using a biphasic electrical current stimulator chip under several different amplitude and duration settings. The experimental scheme for the proliferation assessment is shown in Figure 3A. We initially cultured NSCs to assess proliferation. NSGs were cultured as single adherent cells on laminin-coated surfaces or as the neurospheres and the numbers were counted. In the case of single adherent cell cultures (P3; fetal NSCis after three passages), we investigated the four-day effects of eight different BEC conditions and exposed the fetal NSCs to a $100 \mathrm{~Hz}$ electrical stimulation with a magnitude of 4, 8, 16 and $32 \mu \mathrm{A} / \mathrm{cm}^{2}$ with 50 and $200 \mu \mathrm{s}$ pulses in a continuous manner (Figure 3). We verified that four different electric current conditions did not particularly exert neurotoxicity on fetal NSGs (Figure 3B). The NSCs showed normal adherent cell-like behavior over the laminin-coated ITO surfaces with or without the four different BEC settings (Figure 3C). A more wider range study revealed that the total number of neural stem cells increased, specially using a magnitude ofif the magnitude was set to $8 \mu \mathrm{A} /$ $\mathrm{cm}^{2}$ withfor $200 \mu \mathrm{s}$ pulses $(100 \mathrm{~Hz})$, the total number of NSC count was more than double of controls (ratio $=2.29( \pm 0.21)$ (Figure 3D).
For the neurosphere assay (Figure 4), neurospheres of fetal NSCs were exposed to a $100 \mathrm{~Hz}$ electrical stimulation with a magnitude of 8 and $32 \mu \mathrm{A} / \mathrm{cm}^{2}$ with 50 or $200 \mu$ s pulses in a continuous mode during their proliferation phase (4 days) after three passages (P3). Under the light microscope, we counted both the total number of neurospheres and the number of large neurospheres over $100 \mu \mathrm{m}$ in diameter. The number of neurospheres and their sizes were increased according to the amplitude and duration of BEC stimulation. Particularly, a magnitude of $8 \mu \mathrm{A} / \mathrm{cm}^{2}$ with $200 \mu \mathrm{s}$ pulsed at $100 \mathrm{~Hz}$ exerted the most significant effect ( 3 days: ratio $=2.77 \pm 0.23, \mathrm{p}<0.001 ; 5$ days: ratio $=1.80 \pm 0.11, \mathrm{p}<0.001$ ) (Figure $4 \mathrm{~B}$ ). Although the BEC increased the number of large neurospheres compared to the control (Figure S1B) it did not significantly affect the total number of neurospheres including sub-100 $\mu \mathrm{m}$ sizes (Figure $\mathrm{S1C}$ ). Electrical stimulation with relatively higher amplitudes (i.e., 16, $32 \mu \mathrm{A} / \mathrm{cm}^{2}$ ) or lower pulse durations (i.e., $50 \mu \mathrm{s}$ ) did not significantly affect proliferation (Figure 4).

\section{Electrical stimulation by BEC increased the neuronal population during differentiation of fetal NSCs}

We examined the effects of electrical stimulation by BEC on the differentiation of fetal NSCs into neuronal cells. We exposed the cells to a $100 \mathrm{~Hz}$ electrical stimulation with a magnitude of $1.33,4$ 
(A)

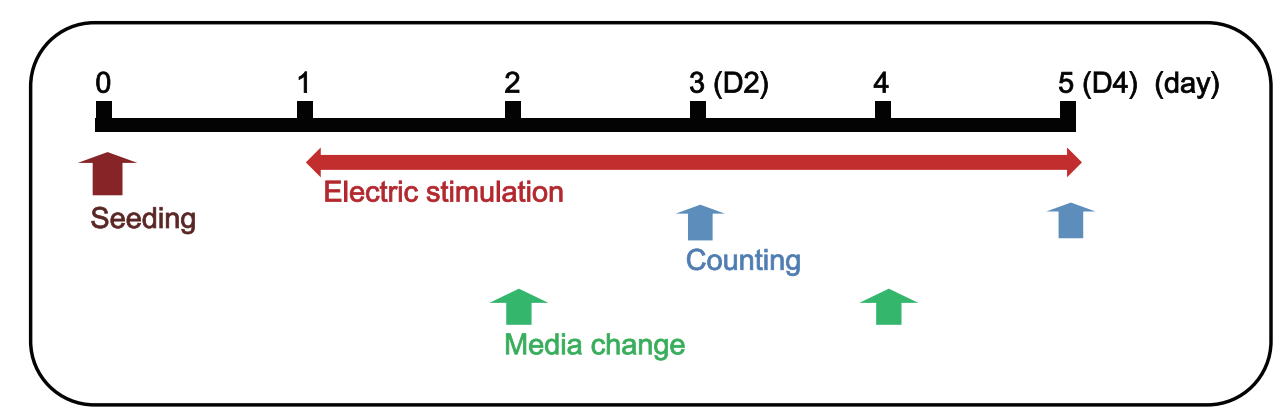

(B)

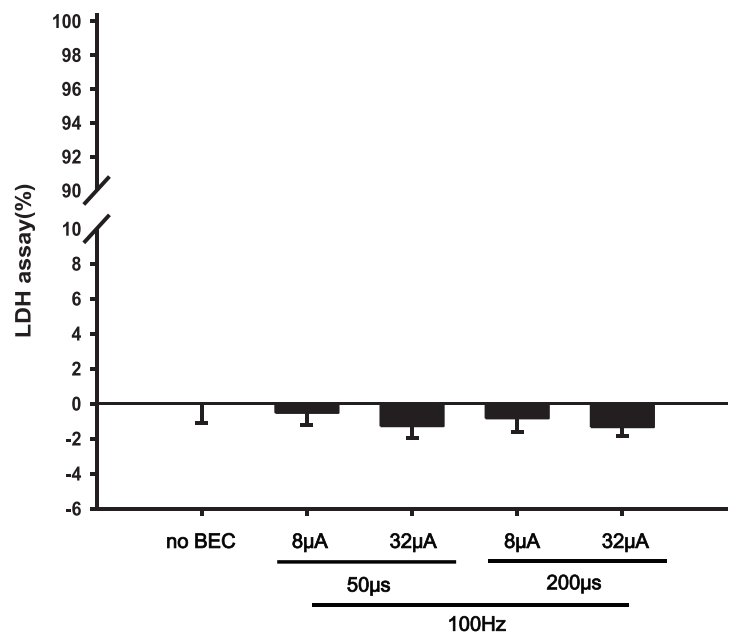

(C)
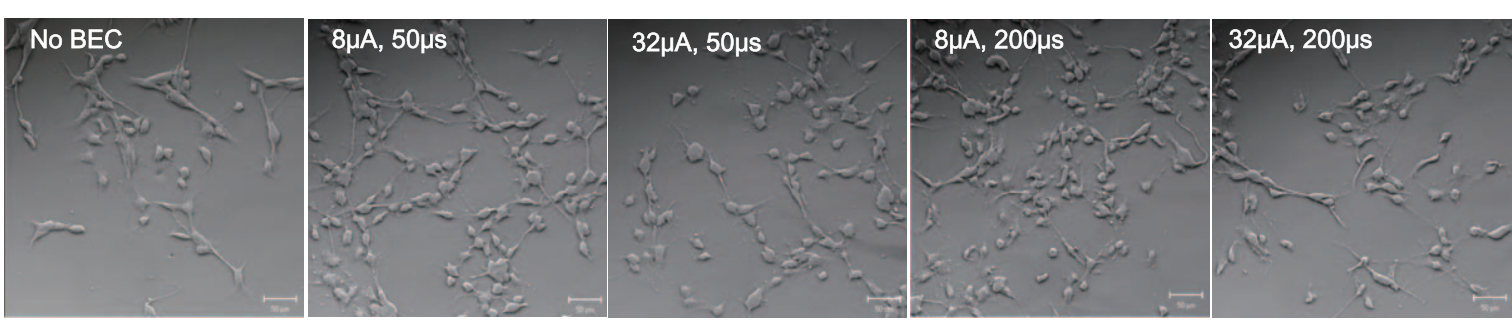

(D)

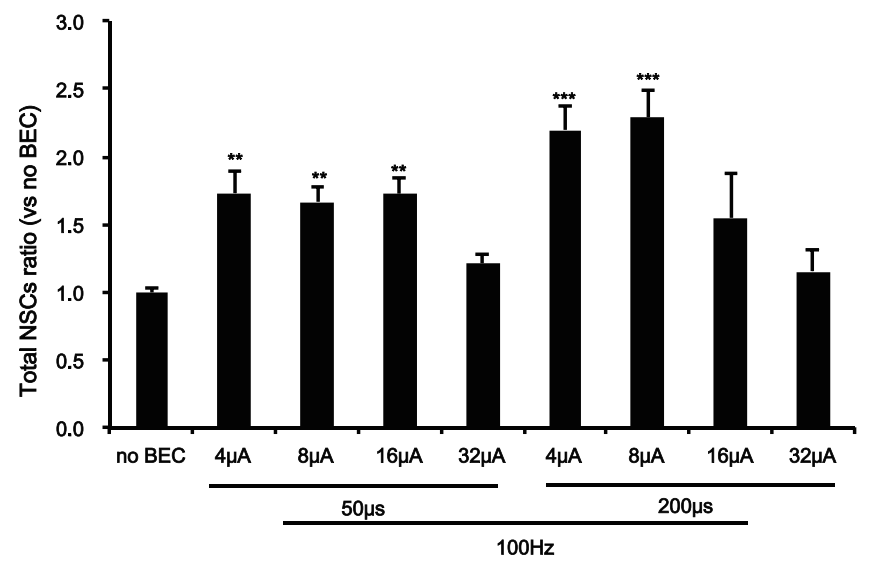


Figure 3. The effects of BEC on the proliferation of fetal NSCs. The stem cells were stimulated at $100 \mathrm{~Hz}$ with a magnitude of $4,8,16$ or $32 \mu \mathrm{A} / \mathrm{cm}^{2}$ and duration of 50 or $200 \mu \mathrm{s}$ for 4 days and then counted the numbers of stem cells. (A) Experimental scheme with the electrical stimulation during the proliferation. (B) Cytotoxicity of BEC in fetal NSCs using LDH assay. Values are expressed as mean \pm SEM of five to eight independent experiments. Data bars are not significantly different from No BEC group by ANOVA with Turkey test. (C) A representative phase contrast micrograph of fetal NSCs produced with each condition of BEC for 4 days; No BEC, $8 \mu \mathrm{A} / \mathrm{cm}^{2}$ for $50 \mu \mathrm{s}, 8 \mu \mathrm{A} / \mathrm{cm}^{2}$ for $200 \mu \mathrm{s}, 32 \mu \mathrm{A} / \mathrm{cm}^{2}$ for $50 \mu \mathrm{s}, 32 \mu \mathrm{A} / \mathrm{cm}^{2}$ for $200 \mu \mathrm{s}$. (D) After 4 days of the electrical stimulation, cell numbers were counted with trypan blue staining. Data represent mean \pm S.E.M. of $n=4-17$. ${ }^{* *}, p \leq 0.01,{ }^{* * *}, p \leq 0.001$; by One-Way ANOVA: Tukey's HSD Post Hoc test.

doi:10.1371/journal.pone.0018738.g003

and $8 \mu \mathrm{A} / \mathrm{cm}^{2}$ with 50 and $200 \mu$ s pulse durations in a continuous manner according to the culture schedule shown in Figure 5A. Cells were fixed with $4 \%$ paraformaldehyde after 4 days and 7 days of exposure to biphasic electric currents (Figure 5A).

Immunofluorescence study was performed using specific antibodies against $\beta$ III-tubulin (Tuj1), which labels neurons in early development as well as mature neurons [18], NeuN (neural nucleus marker), MAP2 (mature neuron marker), and glial fibrillary acidic protein (GFAP) to identify the differentiated level of astrocytic and neuronal populations. In differentiated NSCs treated with or without electrical stimulation, we compared the numbers of neurons stained with anti-Tujl and counterstained with DAPI for nuclear counting (Figure 5 \& 6B). Tujl stains processes as well as cell bodies. Tujl positive cells were counted if a Tuj1 stained cell body included a DAPI stained nucleus to avoid double counting. To confirm whether the Tuj1 positive cells at 4

(A)
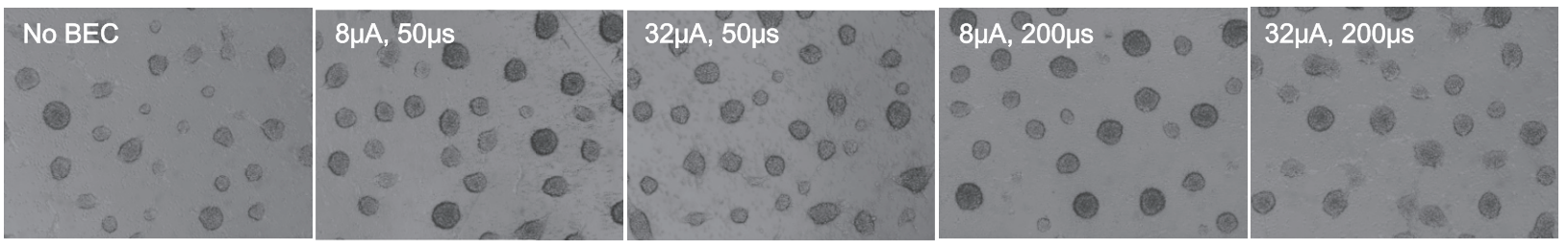

(B)

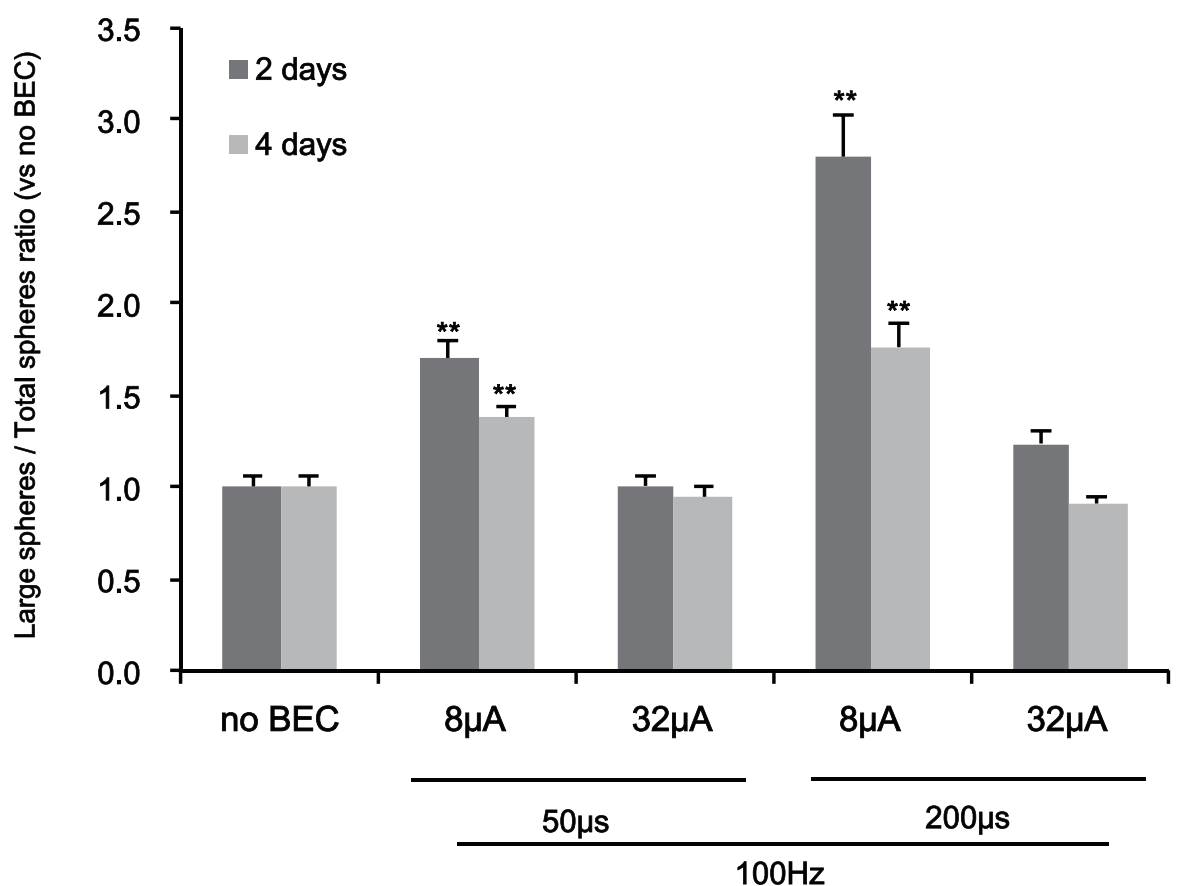

Figure 4. The effects of BEC on the production of neurospheres. For the neurosphere assay, we stimulated them at $100 \mathrm{~Hz}$ with a magnitude of 8 or $32 \mu \mathrm{A} / \mathrm{cm}^{2}$ and duration of 50 or $200 \mu$ s for 2 and 4 days and then counted the numbers of neurospheres after 2 and 4 days of electrical stimulation. (A) A representative phase contrast micrograph of neurospheres produced with four conditions of BEC for 4 days. (B) Ratios of neurospheres greater than $100 \mu \mathrm{m}$ in diameter (large spheres) versus total neurospheres of all sizes (total spheres) after 2 and 4 days of electrical stimulation. Data represent mean \pm S.E.M. of $n=37-52$. ${ }^{* *}, p \leq 0.01,{ }^{* * *}, p \leq 0.001$; by One-Way ANOVA: Tukey's HSD Post Hoc test.

doi:10.1371/journal.pone.0018738.g004 
(A)

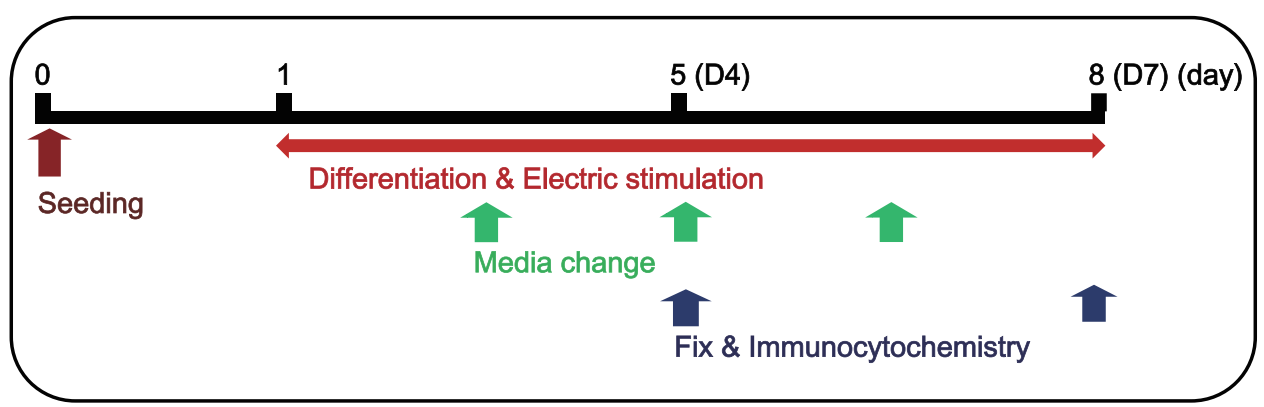

(B)
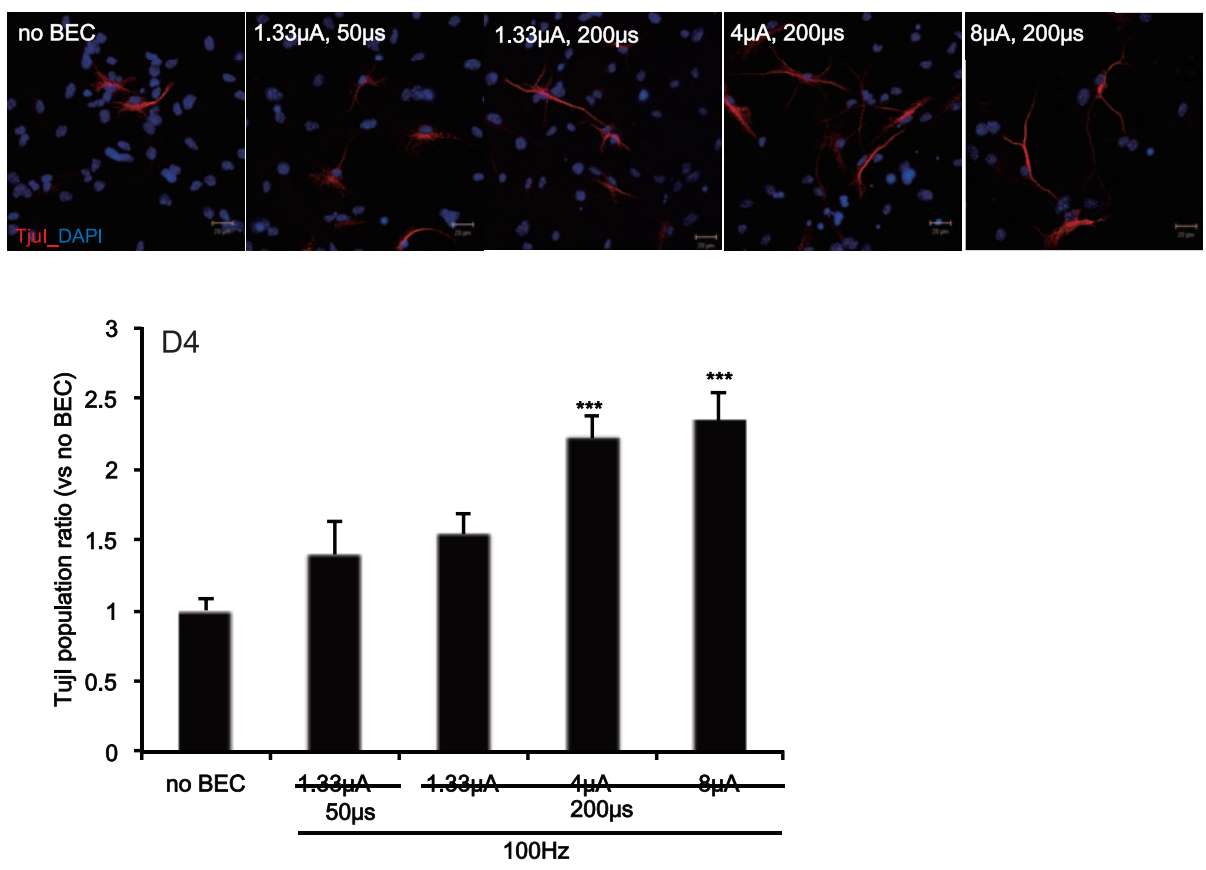

(C)
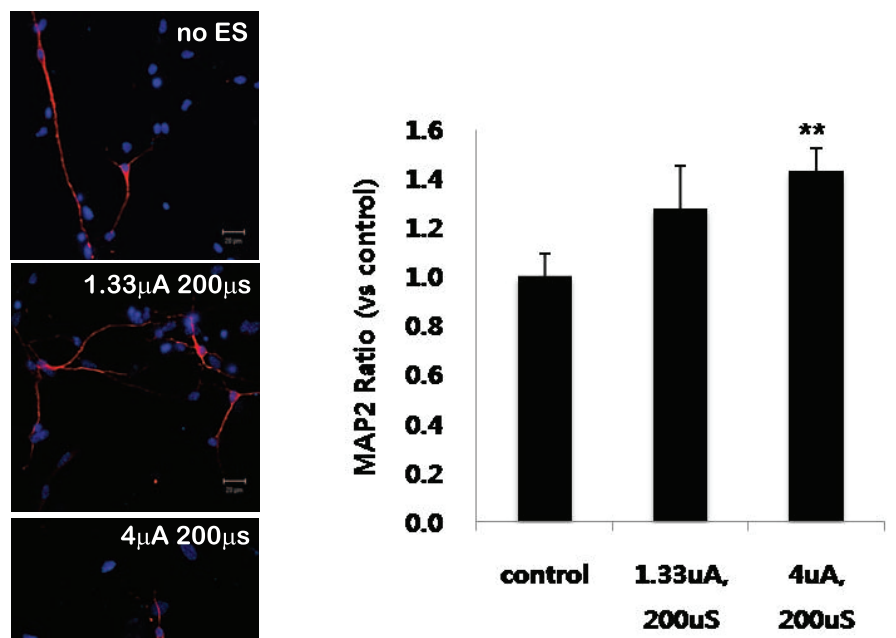
Figure 5. The effects of BEC on the neuronal differentiation during 4 days of differentiation. After 4 days of electrical stimulation at $100 \mathrm{~Hz}$ with a magnitude of $1.33,4$ or $8 \mu \mathrm{A} / \mathrm{cm}^{2}$ and duration of 50 or $200 \mu \mathrm{s}$, Tuj1 immunopositive neurons were counted for all differentiated cells. (A) Experimental scheme for the electrical stimulation during the differentiation. (B) Left panel: The differentiated NSCs were immunostained with anti-Tuj1 (red) antibodies and counterstained with DAPI (blue). Right panel: Counts of Tuj1 immunopositive neurons. DAPI nuclear staining is for the total numbers of neurons. Data represent mean \pm S.E.M. of $n=15-20 .{ }^{* *}, p \leq 0.001$ by One-Way ANOVA: Tukey's HSD Post Hoc test. Scale bar $=20 \mu \mathrm{m}$.

doi:10.1371/journal.pone.0018738.g005

or 7 DIV were neurons, Fixed NSCs were, in addition, stained with NeuN (Figure S2A \& Figure 6B) and MAP2 (Figure S2B \& Figure 6C).

In differentiated NSGs at 4 DIV, the number of cells stained with the anti-Tujl antibody was increased by electrical stimulation compared with those of non-stimulated cells (Figure 5B). However, significant changes in the number of immunoreactive cells were not observed when stained with an anti-NeuN and MAP2 antibodies (Figure S2A \& B). In differentiated NSCs at 7 DIV, the number of cells stained with the anti-Tuj1, NeuN or MAP2 antibodies was increased by electrical stimulation compared with that of non-stimulated cells (Figure 6). Especially, a $100 \mathrm{~Hz}$ electrical stimulation with a magnitude of $4 \mu \mathrm{A} / \mathrm{cm}^{2}$ for $200 \mu \mathrm{s}$ in a continuous mode significantly increased the neuronal differentiation (Figure $5 \& 6$ ). In addition, we checked the proportions of cells positive for neuronal markers such as TujI, NeuN, or MAP2, and for glial marker, GFAP. We found that BEC increased the TujI-population to $17.0 \%\left(1.33 \mu \mathrm{A} / \mathrm{cm}^{2}\right.$ for $\left.200 \mu \mathrm{s}\right)$ and $18.8 \%$ $\left(4 \mu \mathrm{A} / \mathrm{cm}^{2}\right.$ for $\left.200 \mu \mathrm{s}\right)$ compared with the control group $(11.4 \%)$. The populations of NeuN were $9.4 \%$ in control; $14.6 \%$ in $1.33 \mu \mathrm{A} / \mathrm{cm}^{2}$ for $200 \mu \mathrm{s} ; 15.1 \%$ in $4 \mu \mathrm{A} / \mathrm{cm}^{2}$ for $200 \mu \mathrm{s}$. MAP2 positive portions were $9.9 \%$ in control; $13.3 \%$ in $1.33 \mu \mathrm{A} / \mathrm{cm}^{2}$ for $200 \mu \mathrm{s} ; 14.2 \%$ in $4 \mu \mathrm{A} / \mathrm{cm}^{2}$ for $200 \mu \mathrm{s}$. Glial marker, GFAP positive portion were $73.8 \%, 68.0 \%$, and $65.0 \%$ respectively in control, $1.33 \mu \mathrm{A} / \mathrm{cm}^{2}$ for $200 \mu \mathrm{s}$, and $4 \mu \mathrm{A} / \mathrm{cm}^{2}$ for $200 \mu \mathrm{s}$ (Figure S3C). Neuronal cell portions were increased by BEC but glial cell portion was slightly decreased.

\section{Discussion}

The discovery of NSCs in the developing and adult brain that can generate neural tissue has raised new possibilities for repairing the nervous system [4]. The generation of synaptically active neurons from CNS stem cells has implications for the development of new cell therapies [19]. Although many investigators have been working to determine the key regulators of proliferation and the various pathways of differentiation, the fundamental mechanisms that regulate endogenous adult stem cells are poorly understood.

The criteria used to define neuronal differentiation from in vitro expanded stem cells has improved from the first experiments in which morphology and cell type-specific antigens for immature neurons were used ([8], [9]). The differentiation of stem cells to form functional neurons has been reported for cells derived from the substantia nigra [20]. In this case, nestin-positive precursors, expanded in bFGF (basic fibroblast growth factor), differentiated into tyrosine hydroxylase-positive neurons that secreted dopamine and were functional by behavioral tests when grafted into a rat model for Parkinson's disease [20]. Striatal stem cell-derived neuronal precursors preferentially differentiate into GABAergic neurons when exposed to BDNF (brain-derived neurotrophic factor) and other types of neurons after being exposed to insulinlike growth factor-I (IGF-I) [21]. Two neurotrophins, NT-3 and BDNF, influenced the differentiation of hippocampal stem cells into excitatory and inhibitory neurons [22]. However, stem cells can form neurons with functional synapses that respond to neurotrophic factors in similar ways to neurons derived directly from the developing brain [5].
One of the less explored non-chemical strategies for stem cell differentiation is the application of electromagnetic fields (EMF). Although there is enough evidence to believe that EMFs play an important role in cellular differentiation, the mechanism of their interaction with cells including effects on signal transduction pathways, changes in biosynthesis, induction of heat shock proteins (HSPs), and alteration on gene expression is not clear. According to a previous study, EMFs can modulate the initiation of the signal cascade pathways that regulate calcium fluxes [23]. Up- and down-regulation of calcium signaling is assumed to influence subsequences in mitogenesis [23]. EMFs can also induce free radical formation that regulates signal transduction pathway leading to control of gene expression and post translational modification of proteins ([24], [25]). EMFs can, in addition, alter cellular biosynthesis. It has been reported that biphasic electrical current (BEC), coupled with EMF, can up-regulate vascular endothelial growth factor (VEGF) leading to increased proliferation of osteoblasts [26]. The heat shock protein (HSP) activated by electrical stimulation has been shown to promote cellular differentiation. Transient expression of NeuroD2, one of neural basic helix-loop-helix, under the control of HSP activated by electrical stimulation converted mouse neuroblastoma cells into differentiated neurons [27]. The HSP mediated differentiation of human embryonal carcinoma cells into neuronal lineages has been also reported [28]. There is also evidence that EMFs can interact with nucleic acids. Exogenous EMFs may interfere with the endogenous EMFs and may alter gene expression ([29], [30]). Mouse embryonic stem cells will express cardiac lineagepromoting genes when exposed to extremely low frequencies of magnetic field [31].

Differentiation of stem cells into specific cell types will benefit from defined physicochemical properties. The combination of neurotrophic factors and EMFs can potentially enhance the proliferation and promote differentiation of NSCs in a more controlled manner. In regard to EMFs affecting stem cell biology, modulating factors include the wave-shape, frequency, amplitude, and pulse duration. It is supposed that EMFs are most effective when they coordinate with the natural rhythm of a reaction [32]. On the other hand, when the EMF does not coordinate with the natural rhythm, the proliferation and differentiation of NSCs might be inhibited.

This study focused on the proliferation and differentiation of neural stem cells under constant direct biphasic current using a biphasic electrical current (BEC) stimulator chip. The effect of electrical stimulation on the function of neural stem cells was analyzed in vitro for the first time in this study. We examined both the number of total NSCs and the number of neurospheres to determine the effect of the BEC on the proliferation of the neural stem cells (Figure 3,4). We found that the number of large neurospheres $(>100 \mu \mathrm{m})$ increased as well as the number of total neural stem cell counts. Self-renewing stem cells and progenitor cells a believed to comprise a neurosphere [33]. Progenitor cells have limited capacity to self-renew with increased passage numbers; therefore, neurospheres incorporating more progenitor cells will be smaller than those containing more self-renewing stem cells. After multiple days of culture, neurospheres that grew more 
(A)
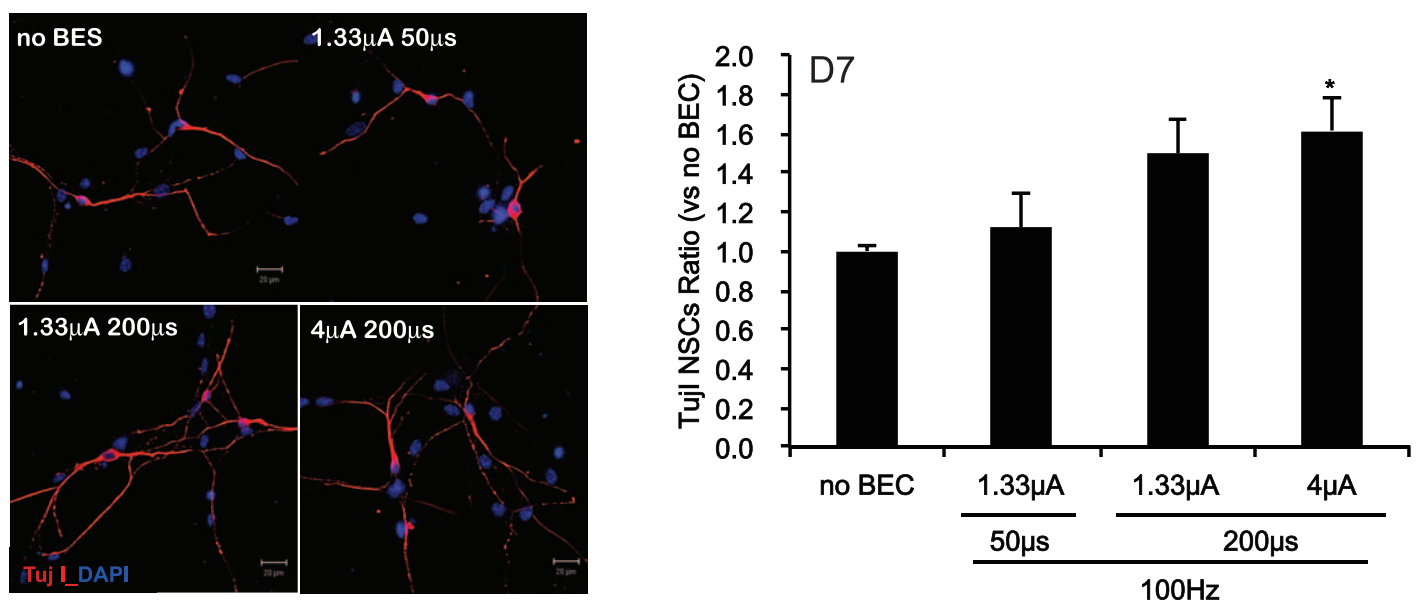

(B)
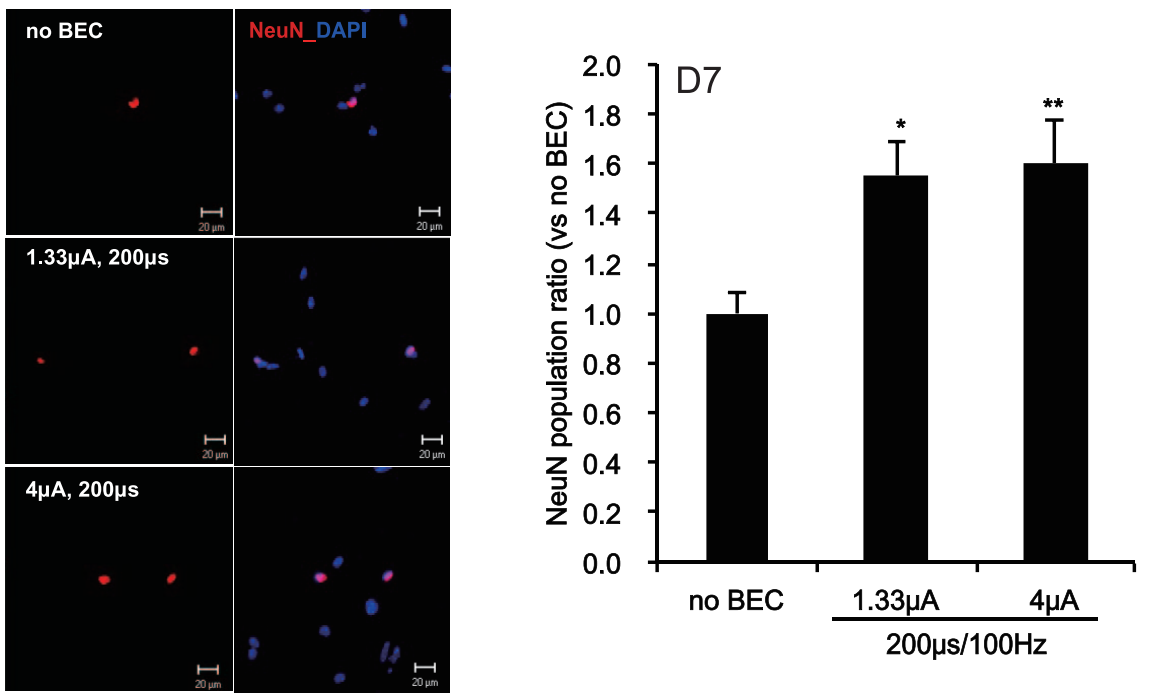

(c)

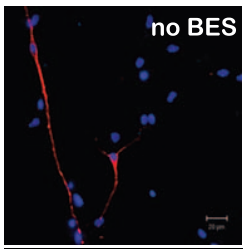

$1.33 \mu \mathrm{A} 200 \mu \mathrm{s}$
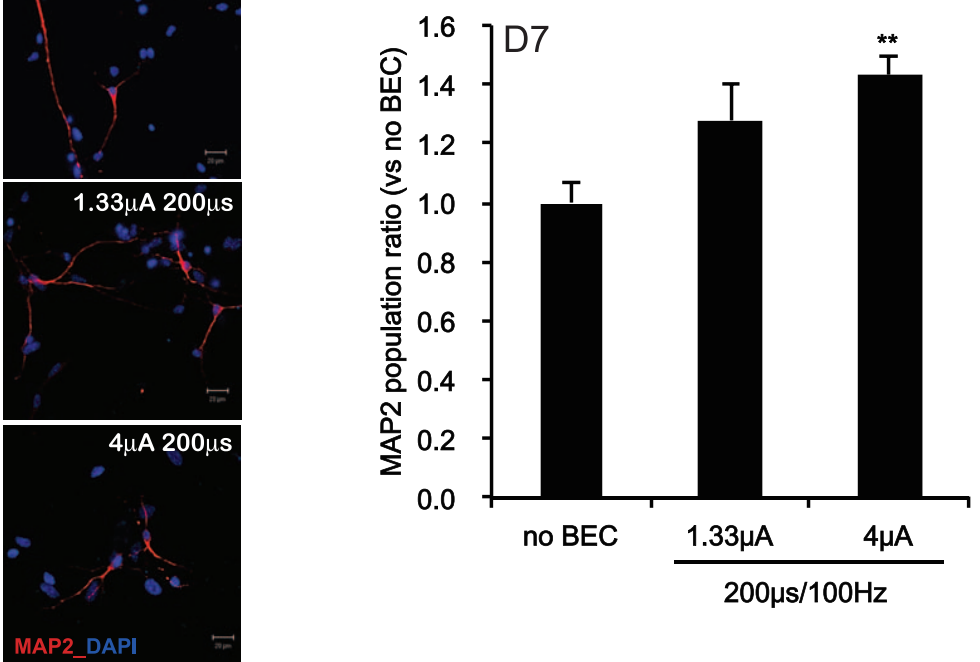
Figure 6. The effects of BEC on the neuronal populations during 7 days of differentiation. At day 7 after exposure to electrical stimulation at $100 \mathrm{~Hz}$ with a magnitude of 1.33 or $4 \mu \mathrm{A} / \mathrm{cm}^{2}$ and duration of 50 or $200 \mu \mathrm{s}$, Tuj1, NeuN or MAP2 immunopositive neurons were counted for all differentiated cells. (A-C) Left panel: The differentiated NSCs were immunostained with anti-Tuj1 ( $A$; red), NeuN (B; red) or MAP2 (C; red) and counterstained with DAPI (blue). Right panel: Counts of Tuj1 (A), NeuN (B) or MAP2 (C) immunopositive neurons. DAPI nuclear staining is for the total numbers of neurons. Data represent mean \pm S.E.M. of $n=25-30 .{ }^{*}, p \leq 0.05,{ }^{*}, p \leq 0.01$ by One-Way ANOVA: Tukey's HSD Post Hoc test. Scale $\operatorname{bar}=20 \mu \mathrm{m}$.

doi:10.1371/journal.pone.0018738.g006

than $100 \mu \mathrm{m}$ in diameter were assessed and thought to contain more self-renewing stem cells than smaller sub-100 $\mu \mathrm{m}$ neurospheres (Figure 4). Thus, it was intriguing to find $8 \mu \mathrm{A} / \mathrm{cm}^{2}$ with $200 \mu$ s pulse durations of BEC $(100 \mathrm{~Hz})$ significantly increased the number of $>100 \mu \mathrm{m}$ neurospheres compared to the control while not essentially affecting the total number of neurospheres.

In addition, we showed that BECs with low amplitude and high pulse duration times $\left(1.33,4 \mu \mathrm{A} / \mathrm{cm}^{2} ; 200 \mu \mathrm{s}\right.$ pulse duration, $100 \mathrm{~Hz}$ ) increased the numbers of NeuN, MAP2 and Tuj1 positive neurons from fetal neural stem cells cultured on laminin coated ITO glass (Figure 5,6). At DIV-4, the population of Tuj1 positive cells in the electrically stimulated groups was significantly increased compared to the control, but the population of NeuN or MAP2 positive neurons did not significantly changed. At DIV-7, the Tuj1 positive neuronal population was also increased compared to the control (1.6-fold), which is similar with those cells positive for $\mathrm{NeuN}$ (1.6-fold) and MAP2 (1.4-fold). We checked differentiation populations after BEC treatment and found that NSCs preferentially differentiated into neuronal cells while glial cell production decreased (Figure S3). It appears long and continuous BEC stimulations can push neural stem cells to undergo neuronal differentiation.

In conclusion, our work suggests that (1) current densities greater than $1 \mu \mathrm{A} / \mathrm{cm}^{2}$ or less than $30 \mu \mathrm{A} / \mathrm{cm}^{2}$ for $200 \mu \mathrm{s}$ at $100 \mathrm{~Hz}$ will positively affect the proliferation and the neural differentiation of fetal neural stem cells in our BEC culture system, (2) electrical stimulation at a calculated current density of 4 or $8 \mu \mathrm{A} / \mathrm{cm}^{2}$ for $200 \mu \mathrm{s}$ at $100 \mathrm{~Hz}$ showed the greatest increase in proliferation, and (3) neural differentiation of fetal neural stem cells is significantly increased with $4 \mu \mathrm{A} / \mathrm{cm}^{2}, 200 \mu \mathrm{s}(100 \mathrm{~Hz})$ electrostimulation condition.

This in vitro study advances our understanding of how electric fields can alter fetal neural stem cell biology and can potentially contribute to the development of new stem cell therapies for various neurodegenerative diseases.

\section{Materials and Methods}

\section{Preparation of fetal neural stem cells (fetal NSCs)}

Fetal neural stem cells were derived from the cerebral cortices of the embryos (E13 days) of 6- to 7-week-old pregnant C57BL/6 mice (Japan SLC. Inc, Haruno Breeding Branch). Briefly, an anesthetized pregnant mouse was exposed to an overdose inhalation of 70-100\% $\mathrm{CO}_{2}$ gas for euthanasia, and then the uterus was extracted into cold PBS. We collected embryos in cold PBS and then moved them into a filtered flask to administer euthanasia using an overdose inhalation of $70-100 \% \mathrm{CO}_{2}$ gas. $\mathrm{CO}_{2}$ was chosen because it induced anesthesia and euthanasia rapidly and was highly effective. Next, we placed them in a fresh dish with PBS. Using curved, sharp forceps, the brains were collected from the embryos under a microscope. All animal experimental procedures were performed in accordance with 'the Guidelines of the Ethics Committee at Seoul National University' (SNU 091208-1).

\section{NSCs proliferation and differentiation}

The generation of neurospheres derived from the neural stem cells of the cerebral cortices of mice was performed as described previously [9]. The NSCs were aggregated into neurospheres when subsequently plated and cultured in the proliferating media, DMEM/F12 (1:1) (Gibco, NY). The medium was supplemented with $2 \mathrm{mM}$ L-glutamine (Gibco), $0.6 \%$ glucose, $5 \mu \mathrm{M}$ HEPES, $25 \mu \mathrm{g} / \mathrm{ml}$ insulin, $100 \mu \mathrm{g} / \mathrm{ml}$ apo-transferrin, $30 \mathrm{nM}$ sodium selenite, $100 \mathrm{nM}$ putrescine and $20 \mathrm{nM}$ progesterone (all supplements purchased from Sigma, St. Louis) with growth factors of $10 \mathrm{ng} / \mathrm{ml}$ recombinant bFGF (Roche, Mannheim, Germany) and $20 \mathrm{ng} / \mathrm{ml} \mathrm{EGF} \mathrm{(BD} \mathrm{sciences,} \mathrm{MA)} \mathrm{at} \mathrm{a} \mathrm{density} \mathrm{of} 2 \times 10^{6}$ cells in T75 flask (TPP, Switzerland) for 5 days. The neurospheres were then trypsinized (Trypsin EDTA, Gibco), triturated to a single-cell suspension, passaged in culture 3-5 times (P3-P5) with the media, and plated at a density of $5 \times 10^{4}$ cells/well in the ITO glasses.

For the cell differentiation experiment, neurospheres were trypsinized (Trypsin EDTA, Gibco), triturated to a single-cell suspension, plated on the ITO glasses coated with Laminin (Roche), and then cultured in the differentiation media without growth factors (EGF and bFGF) for 4 or 7 days (4 DIV or 7 DIV). They were then assessed by immunocytochemistry.

\section{Biphasic electrical current stimulator chip (BECSC)}

A biphasic current stimulator chip was fabricated using a $0.8-$ $\mu \mathrm{m}$ high-voltage complimentary metal-oxide semiconductor fabrication process at Austria Micro-Systems Corporation as described previously [34]. The chip was designed to generate continuous biphasic current pulses with diverse electrical parameters. The electrical parameters, such as amplitude, pulse width, and pulse rate, were programmable in the ranges of $2-1,024 \mu \mathrm{A}$ (2 $\mu \mathrm{A}$ step, 512 levels), 25-775 $\mu$ s (25 $\mu$ s stepwise, 32 levels), and 5-3000 Hz (64 levels) respectively. An electrostatic discharge protector was built at all input and output pads of the chip to protect the circuit from external shock. An electrical short circuit between the reference electrode and stimulation electrode was also added in order to ensure safe electrical stimulation and discharge charges accumulated by the asymmetry between positive and negative phases. Figure $1 \mathrm{~A}$ shows a circuit diagram of the stimulator chip. Biphasic current is generated by the complementary switching between ???, ??? and ???, ??? switches. The amplitude of the biphasic current is controlled stepwise by a 9bit current digital to analog converter (DAC). The biphasic current pulses generated by the current stimulator were charge-balanced to avoid unintended chemical reactions by charge accumulation. Figure 1B shows a biphasic current stimulator where the stimulator chips, on/off power switch, and switches for parameter settings are installed. Figure $1 \mathrm{C}$ explains the current pulses.

\section{In vitro culture system on a biphasic electrical current stimulator chip}

An in vitro culture system was designed in which dissociated NSCs could be cultivated and stimulated electrically. The culture system was made of Indium Tin Oxide (ITO) glass and Teflon jigs for biocompatibility with neuronal stem cells. The ITO glass with high electrical conductivity is so transparent that it is easy to observe cells through a microscope. Teflon is known to be excellent in chemical endurance and mechanical stability. Figure 2 shows a photo and a schematic drawing of the culture system. As shown in Figure 2B, 
two ITO glasses working as a stimulation electrode and a reference electrode were placed in parallel to deliver uniform current to the cells. The Teflon jigs formed culture chambers with the ITO glasses, and printed circuit boards (PCBs) were inserted for the connection between the ITO glass and the biphasic current stimulator. The in vitro culture system consisted of six identical chambers that were connected to the biphasic current stimulator (Figure 2A \& 2B). Before and after assembly, all parts, including ITO glass and Teflon jig, went through a cleaning process using acetone, 70\% ethanol, and de-ionized water for $15 \mathrm{~min}$. After assembly, the culture system was also sterilized by plasma cleaner for 5 minutes.

\section{Antibodies}

The primary antibodies used were as follows: rabbit polyclonal anti-glial fibrillary acidic protein (GFAP; 1:500, Dako, CA); mouse monoclonal anti-BIII-tubulin (Tuj1; 1:1000, Promega, CA); mouse anti-MAP2 monoclonal antibody (1:500, Sigma); mouse antineuronal nuclei (NeuN; 1:1000, Chemicon). The secondary antibodies used were as follows: Alexa fluor ${ }^{\circledR} 568$ goat anti-mouse $\operatorname{IgG}(\mathrm{H}+\mathrm{L})$ and Alexa fluor ${ }^{\circledR} 488$ goat anti-rabbit $\operatorname{IgG}(\mathrm{H}+\mathrm{L})$ (1:1000, Molecular probes, Eugene, OR).

\section{Immunofluorescence and confocal microscopy}

Cells grown on coated ITO glasses in a biphasic current stimulator chip were fixed for 20 min with $4 \%$ paraformaldehyde in PBS, pH 7.4, and rinsed three times with PBS. ITO glasses then were incubated for $60 \mathrm{~min}$ at room temperature (RT) or overnight at $4{ }^{\circ} \mathrm{C}$ in PBS containing $4 \%$ NGS (normal goat serum, Vector laboratories, CA), $0.2 \%$ Triton X-100, 2\% BSA (bovine serum albumin, Sigma), 2\% FBS (fetal bovine serum, HyClone, Logan, UT) and the appropriate primary antibodies. After washing with PBS, the cells were reacted for $60 \mathrm{~min}$ at RT in the dark with the secondary antibody. ITO glasses were rinsed three times with PBS and mounted on glass slides with fluorescent mounting medium (DakoCytomation, CA).

After immunostaining, specimens were examined on a Zeiss LSM 510 confocal imaging system (Zeiss, Heidelberg, Germany) for immunofluorescence imaging. We also used this system for measuring the clonal diameter after immunostaining of the differentiating clones with neuronal markers.

\section{Cell toxicity Assay}

The effect of BEC on cell toxicity was determined using LDH assay. The cells were examined 5 days during the BEC stimulation with various conditions. $\mathrm{LDH}$ activities in the medium were measured by a Cytotox 96 nonradioactive cytotoxicity assay kit (Promega) according to the manufacturer's instructions. Absorbance was measured at $490 \mathrm{~nm}$ with an ELISA reader (Molecular devices, CA). The results were expressed as percentages of peak $\mathrm{LDH}$ release obtained on addition of vehicle $(0 \%)$, and complete cell lysis following addition of $10 \%$ Triton X-100 treatment (100\%).

\section{Evaluation of the proliferation and neural differentiation of NSCs}

We cultured NSGs in the form of single cell on coated biphasic current stimulator chip or in the sphere form on uncoated BEC chip under stimulating at $100 \mathrm{~Hz}$ with a magnitude of $4,8,16$ or $32 \mu \mathrm{A}$ / $\mathrm{cm}^{2}$ for 50 or $200 \mu \mathrm{s}$ with the experimental scheme (Figure 3A). After 4 days of the electrical stimulation, both the numbers of total stem cells and the numbers of neurospheres were counted. Cell numbers were counted with trypan blue staining under the light microscopy. For the proliferation assay of the neurospheres, we attached a grid-inscribed scale $(10 \mu \mathrm{m} \times 10 \mu \mathrm{m})$ on the eyepiece in the light microscope (NIKON, Japan) and directly counted the spheres that were more than $100 \mu \mathrm{m}$ in diameter. Data represent mean \pm S.E.M. of $n=4-17$ independent experiments.

For quantitative evaluation of neural differentiation with immunocytochemical data, the stem cells were stimulated at $100 \mathrm{~Hz}$ with a magnitude of $1.33,4$ or $8 \mu \mathrm{A} / \mathrm{cm}^{2}$ for 50 or $200 \mu \mathrm{s}$ with the experimental scheme with the electrical stimulation during the differentiation (Figure 4A). The number of immunereactive cells against the neuronal marker was counted and calculated on the basis of DAPI (Molecular Probes, Eugene, OR) stained total immunoreactive cells within the area. Data represent mean \pm S.E.M. of $n=15-20$ independent experiments.

\section{Statistical analysis}

Data are expressed as the mean \pm standard error of the mean (SEM) for triplicate or quadrant repeats with six independent samples $(n>15)$ for the analyses of proliferation or differentiation. The results were statistically analyzed by the one-way ANOVA: Tukey's HSD Post Hoc test using PASW statistics (SPSS version 18). The difference was considered statistically significant for $*, p \leq 0.05, * *, p \leq 0.01$, and ***, $p \leq 0.001$.

\section{Supporting Information}

Figure S1 The effects of BEC on the neuronal populations during 4 days of differentiation. The stem cells were stimulated at $100 \mathrm{~Hz}$ with a magnitude of $4,8,16$ or $32 \mu \mathrm{A} / \mathrm{cm}^{2}$ and duration of 50 or $200 \mu \mathrm{s}$. (A) A phase contrast micrograph of neurospheres after 4 days of electrical stimulation with grid of $100 \mu \mathrm{m}$. (B) Counts of neurospheres greater than $100 \mu \mathrm{m}$ in diameter after 2 and 4 days of electrical stimulation. (C) Counts of total neurospheres of all sizes after 2 and 4 days of electrical stimulation. Data represent mean \pm S.E.M. of $n=4-17$. **, $p \leq 0.01$, ***, $p \leq 0.001$ by One-Way ANOVA: Tukey's HSD Post Hoc test.

(EPS)

Figure S2 The effects of BEC on the neuronal populations during 4 days of differentiation. After 4 days of exposure to electrical stimulation at $100 \mathrm{~Hz}$ with a magnitude of $1.33 \mu \mathrm{A} / \mathrm{cm}^{2}$ and duration of 50 or $200 \mu \mathrm{s}$, NeuN or MAP2 immunopositive neurons were counted for all differentiated cells. (A\&B) Left panel: The differentiated NSCs were immunostained with anti-NeuN (A; red) or anti-MAP2 (B; red) and counterstained with DAPI (blue). Right panel: Counts of NeuN (A) or MAP2 (B) immunopositive neurons. DAPI nuclear staining is for the total numbers of neurons. Data represent mean \pm S.E.M. of $n=10-15$. Data was statistically analyzed by One-Way ANOVA: Tukey's HSD Post Hoc test. Scale bar $=20 \mu \mathrm{m}$.

(EPS)

Figure S3 The effects of BEC on the neuronal populations during 7 days of differentiation. The differentiated NSCs at DIV-7 were immunostained with anti-Tujl (A; red) or anti-MAP2 (B; red) and anti-GFAP (green) antibodies and counterstained with DAPI (blue). (C) The proportions for each cell marker of NeuN, MAP2, Tuj1, and GFAP. (EPS)

\section{Author Contributions}

Conceived and designed the experiments: K-AC JWK SJK Y-HS. Performed the experiments: K-AC JWK JaK. Analyzed the data: K-AC JWK JaK SJK Y-HS. Contributed reagents/materials/analysis tools: SL H-SK S. Kwon. Wrote the paper: K-AC JWK H-SK SJK Y-HS. Edit the manuscript: S. Kim WHS S. Kwon. 


\section{References}

1. Gage FH (2000) Mammalian neural stem cells. Science 287: 1433-1438.

2. Gritti A, Parati EA, Cova L, Frolichsthal P, Galli R, et al. (1996) Multipotential stem cells from the adult mouse brain proliferate and self-renew in response to basic fibroblast growth factor. J Neurosci 16: 1091-1100.

3. Luskin MB (1994) Neuronal cell lineage in the vertebrate central nervous system. FASEB J 8: 722-730.

4. Storch A, Schwarz J (2002) Neural stem cells and neurodegeneration. Curr Opin Investig Drugs 3: 774-781.

5. Vicario-Abejon C, Collin C, Tsoulfas P, McKay RD (2000) Hippocampal stem cells differentiate into excitatory and inhibitory neurons. Eur J Neurosci 12: 677-688.

6. Ge S, Goh EL, Sailor KA, Kitabatake Y, Ming GL, et al. (2006) GABA regulates synaptic integration of newly generated neurons in the adult brain. Nature 439: 589-593.

7. Heng BC, Cao T, Haider HK, Wang DZ, Sim EK, et al. (2004) An overview and synopsis of techniques for directing stem cell differentiation in vitro. Cell Tissue Res 315: 291-303.

8. Cattaneo E, McKay R (1990) Proliferation and differentiation of neuronal stem cells regulated by nerve growth factor. Nature 347: 762-765.

9. Reynolds BA, Tetzlaff W, Weiss S (1992) A multipotent EGF-responsive striatal embryonic progenitor cell produces neurons and astrocytes. J Neurosci 12: 4565-4574.

10. Johe KK, Hazel TG, Muller T, Dugich-Djordjevic MM, McKay RD (1996) Single factors direct the differentiation of stem cells from the fetal and adult central nervous system. Genes Dev 10: 3129-3140.

11. Marmur R, Kessler JA, Zhu G, Gokhan S, Mehler MF (1998) Differentiation of oligodendroglial progenitors derived from cortical multipotent cells requires extrinsic signals including activation of gp130/LIFbeta receptors. J Neurosci 18: 9800-9811.

12. Kalyani AJ, Piper D, Mujtaba T, Lucero MT, Rao MS (1998) Spinal cord neuronal precursors generate multiple neuronal phenotypes in culture. J Neurosci 18: 7856-7868.

13. Pappas IS, Parnavelas JG (1997) Neurotrophins and basic fibroblast growth factor induce the differentiation of calbindin-containing neurons in the cerebral cortex. Exp Neurol 144: 302-314.

14. Takahashi J, Palmer TD, Gage FH (1999) Retinoic acid and neurotrophins collaborate to regulate neurogenesis in adult-derived neural stem cell cultures. J Neurobiol 38: 65-81.

15. Kirschenbaum B, Goldman SA (1995) Brain-derived neurotrophic factor promotes the survival of neurons arising from the adult rat forebrain subependymal zone. Proc Natl Acad Sci U S A 92: 210-214.

16. Markwardt SJ, Wadiche JI, Overstreet-Wadiche LS (2009) Input-specific GABAergic signaling to newborn neurons in adult dentate gyrus. J Neurosci 29: $15063-15072$

17. Markwardt S, Overstreet-Wadiche L (2008) GABAergic signalling to adultgenerated neurons. J Physiol 586: 3745-3749.

18. Menezes JR, Luskin MB (1994) Expression of neuron-specific tubulin defines a novel population in the proliferative layers of the developing telencephalon. J Neurosci 14: 5399-5416.
19. Svendsen CN, Smith AG (1999) New prospects for human stem-cell therapy in the nervous system. Trends Neurosci 22: 357-364.

20. Studer L, Tabar V, McKay RD (1998) Transplantation of expanded mesencephalic precursors leads to recovery in parkinsonian rats. Nat Neurosci 1: 290-295.

21. Arsenijevic Y, Weiss S (1998) Insulin-like growth factor-I is a differentiation factor for postmitotic CNS stem cell-derived neuronal precursors: distinct actions from those of brain-derived neurotrophic factor. J Neurosci 18: 2118-2128.

22. Labelle C, Leclerc N (2000) Exogenous BDNF, NT-3 and NT-4 differentially regulate neurite outgrowth in cultured hippocampal neurons. Brain Res Dev Brain Res 123: 1-11.

23. Felaco M, Reale M, Grilli A, De Lutiis MA, Barbacane RC, et al. (1999) Impact of extremely low frequency electromagnetic fields on CD4 expression in peripheral blood mononuclear cells. Molecular and Cellular Biochemistry 201: 49-55.

24. Abe J, Berk BC (1998) Reactive oxygen species as mediators of signal transduction in cardiovascular disease. Trends in Cardiovascular Medicine 8: 59-64.

25. Rollwitz J, Lupke M, Simko M (2004) Fifty-hertz magnetic fields induce free radical formation in mouse bone marrow-derived promonocytes and macrophages. Biochimica Et Biophysica Acta-General Subjects 1674: 231-238.

26. Kim IS, Song JK, Zhang YL, Lee TH, Cho TH, et al. (2006) Biphasic electric current stimulates proliferation and induces VEGF production in osteoblasts. Biochim Biophys Acta 1763: 907-916.

27. Mie M, Endoh T, Yanagida Y, Kobatake E, Aizawa M (2003) Induction of neural differentiation by electrically stimulated gene expression of NeuroD2. Journal of Biotechnology 100: 231-238.

28. Yamada T, Hashiguchi A, Fukushima S, Kakita Y, Umezawa A, et al. (2000) Function of $90-\mathrm{kDa}$ heat shock protein in cellular differentiation of human embryonal carcinoma cells. In Vitro Cellular \& Developmental Biology-Animal 36: 139-146.

29. Matzke MA, Matzke AJM (1996) Electric fields and the nuclear membrane. Bioessays 18: 849-850.

30. Blank M, Goodman R (2004) Initial interactions in electromagnetic fieldinduced biosynthesis. Journal of Cellular Physiology 199: 359-363.

31. Ventura C, Maioli M, Asara Y, Santoni D, Mesirca P, et al. (2004) Turning on stem cell cardiogenesis with extremely low frequency magnetic fields. Faseb Journal 18: 155-+

32. Ahuja YR, Bhargava SC, Ratnakar KS (2005) Electric and magnetic fields in stem cell research. Electromagnetic Biology and Medicine 24: 121-134.

33. Reynolds BA, Rietze RL (2005) Neural stem cells and neurospheres - reevaluating the relationship. Nat Methods 2: 333-336.

34. Song JK, Cho TH, Pan H, Song YM, Kim IS, et al. (2009) An electronic device for accelerating bone formation in tissues surrounding a dental implant. Bioelectromagnetics 30: 374-384. 